\title{
THE PROBLEM OF ARCHITECTURE \& URBAN IDENTITY OF CAMPUS BUILDINGS IN NEW COMMUNITIES
}

\author{
Dr.Ehab nasr Elden Ahmed mohamed \\ Department of Architecture, Faculty of Engineering, Mataria, Helwan \\ University
}

(Received October 12, 2011 Accepted March 8, 2012)

New University Campus buildings, new urban communities is the center of cultural and civilizational radiation because of their scientific value, symbolic and factor interact with the identity and character of the place. It has become suffering from lack of respect for the identity of a local architectural, urban and cultural heritage of the place as a result of an extensive and varied intellectual, which occurred as the product of the stage of modernism and different orientations and self-views, both architects or owners of the universities and foreign institutes in a case dealing with the architectural identity.

This study discusses the correlation between the urban and architectural identity of the campus buildings and space, studying the different experiences, which has respected the identity and character of the place, Through the study and analysis of some examples in the local reality and the new urban communities in order to take advantage of the serious examples which respects the importance of architectural identity and the cultural heritage of the place, especially of university buildings when building in a society with a characteristic cultural, heritage and unique identity .

\section{د. إيهاب نصر الدين أحمد محمد$$
\text { مدرس بقسم الهندسة المعدارية ، كلية الهندسة بالمطرية ، جامـعة حلـوان }
$$ \\ إشكالية الهوية المعمارية والعمرانية للمباني الجامعية بالتجمعات العمرانية الجديدة}

تعتبر المباني الجامعية بدورها الهام فى دعم وتعزيز الإنتماء لدى أفراد المجتمع _كمركز إشعاعي وثقافي _عاملاً مؤثراً تتفاعل مع هوية وطابع المكان، يناقش البحث العلاقة التبادلية بين الهوية المعمارية والعمرانية للمباني الجامعية والمكان ومعرفة أدوات دعم الهوية، ومناقشة التوجهات المختلفة فى التعامل مع هوية هذه المباني ودراسة بعض التجارب المختلفة التي تعاملت مع هوية وطابع المكان وذللك من خلال دراسة وتحليل بعض الأمتلة في واقعنا المحلى بالتجعات العمرانية الجديدة بهدف الإستفادة من الأمثلة الجادة التي تعي إحترام أهمية الهوية المعمارية والعمرانية وإحترام الموروث الثقافي للمكان وبخاصة للمباني الجامعية سواء المحلية منها أو الأجنبية عند البناء فى مجتمع له موروث ثقافى وهوية واضحة، ويسنتتج البحث بأن يكون النظر إلى مسألة الهوية المعمارية للمباني الجامعية من منظور ثقافي ذو دلالة مكانية والتي بتطلب الحفاظ عليها والوعى والإدراك بأهميتها وأهمية التطور مع توصية البحث بالإستفادة من الإطار الفكرى المقترح عند تصميم المباني الجامعية لدعم دور 
الهوية الإيجابى وإستخدام أدوات هذا الدعم فى تحقيق هوية الدكان، وضرورة مراعاة إحترام الهوية المعمارية والعمرانية والموروث الثقافى للمكان وتفعيل دورها فى ذلك، مع الإستفادة من التجارب المعمارية المحلية الرائدة

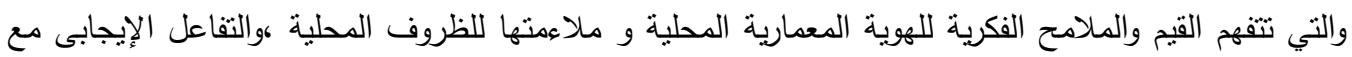
متغيرات العلم والفكر وذلك لدحاولة النطبيق وإعادة التقييم لتحقيق عملية النطوير والإستمرار.

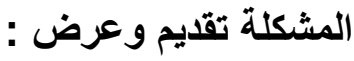

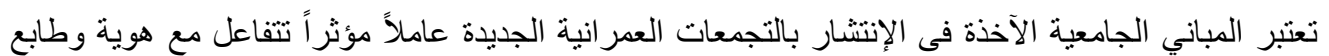

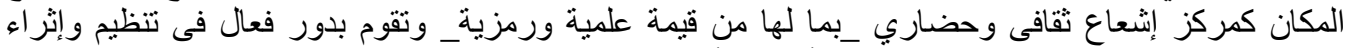

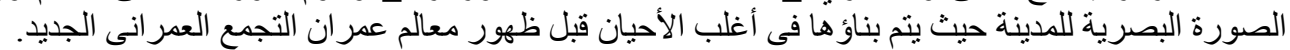

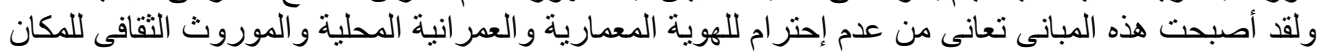

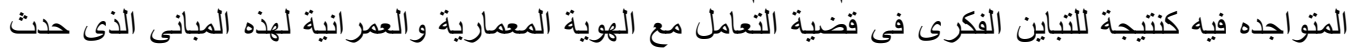

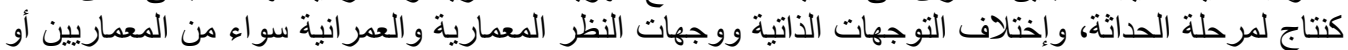
ملاكك الجامعات و المعاهد أو البلد التى تلتنمى إليها.

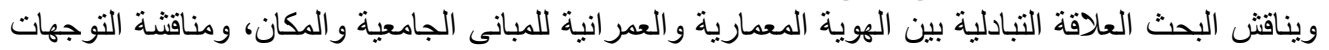

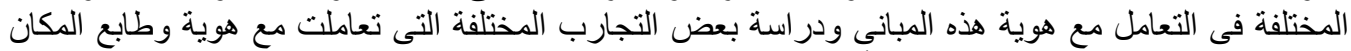

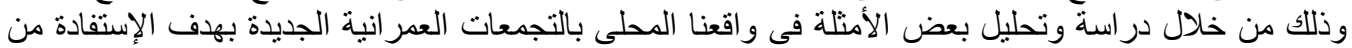

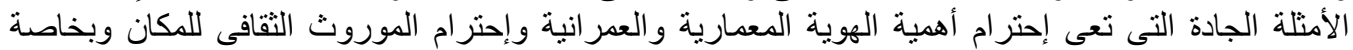

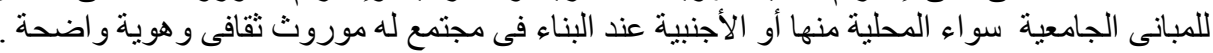

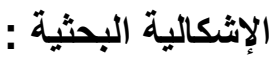

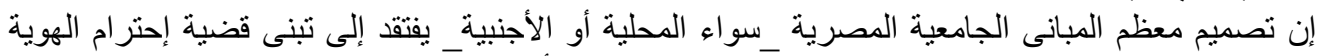

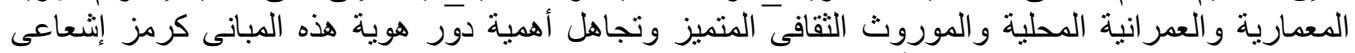
وثقافى فى دعم وتعزيز الإنتماء لدى أفراد المجتمع. أهداف البحث : تهدف الدراسة في هذا البحث إلى تحقيق ما يلي : ـ الإستفادة من النجارب الناجحة فى مجال إحترام الهوية المعمارية و العمر انية المحلية و الإستجابة للموروث

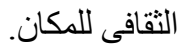

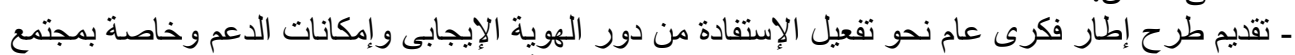

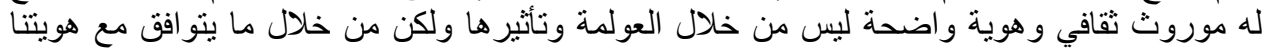

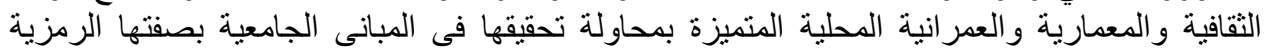
التعزيز الإتنماء لاى أفر اد المجتمع المحيط.

منهجية البحث :

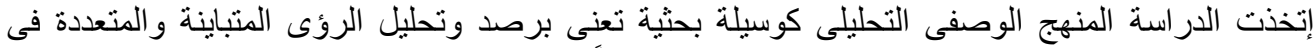

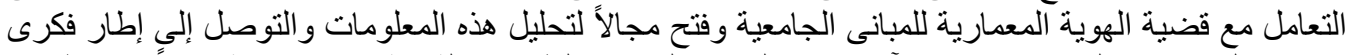

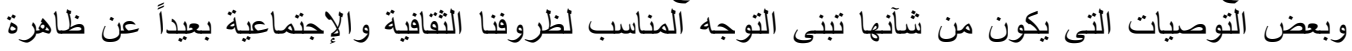

$$
\text { تتناول الدراسة النقاط الأتية للوصول إلى أهداف البحث:- }
$$

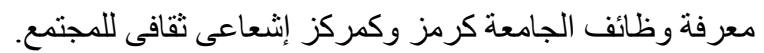

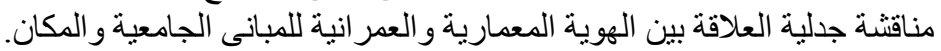

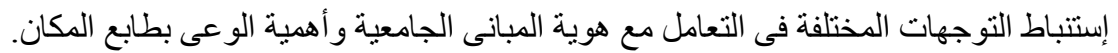

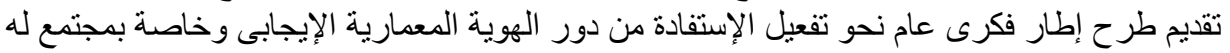
موروث ثقافي و هوية واضحة و إمكانات دعم الهوية للمبانى الجامعية. 


\section{1- وظائف الجامعة كمركز إثعاعي ثقافي بالنسبة للمجتمع والبيئة المحيطة :}

لقد أصبحت الجامعة فى العصر الحديث ذات دوراً هاماً ومؤثراً فى تشكيل مستقبل الأمة فهى تخاطب روت روح

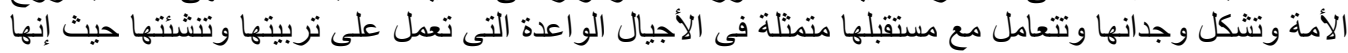

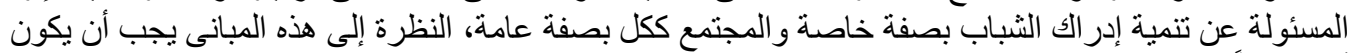

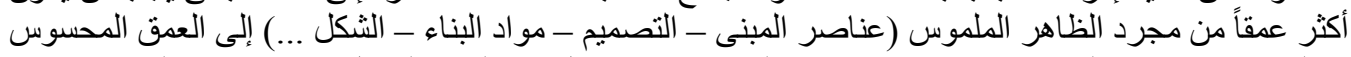

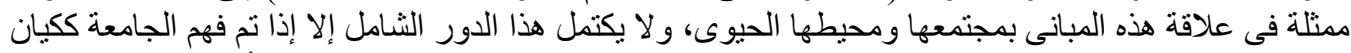

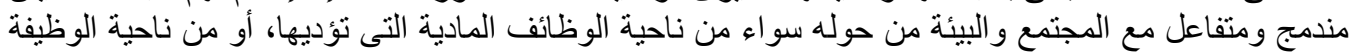

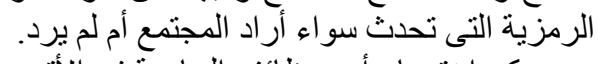

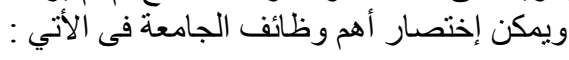

\section{1/1 الوظيفة التعليمية :}

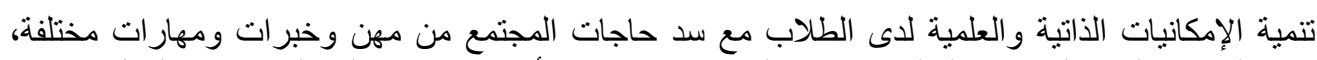

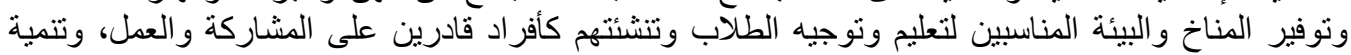

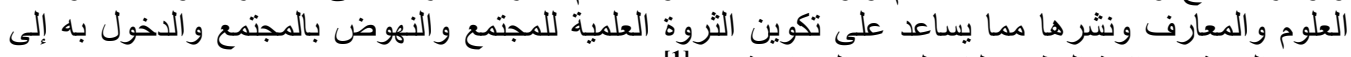

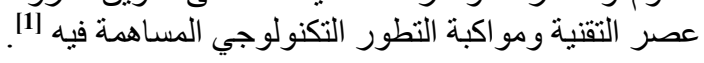

2/1 الوظيفة الثقافية :

العمل على تثقيف الفرد وتنمية معارفه ليكون عضو فعال بالمجتمع بإعتبار ها منارة ثقافية, مع صهر التقاليد

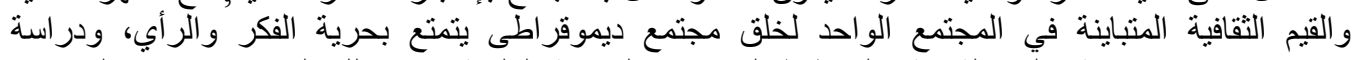

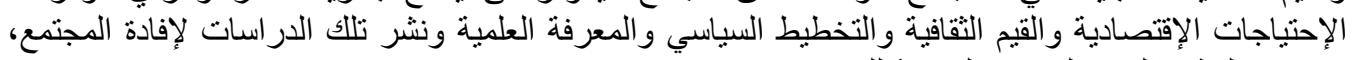
وترسيخ النظم و القيم و المعايير اللازيمة ولفيم للتقدم .

\section{: 3/1 الوظيفة الإجتماعية}

يؤدى حدوث التفاعل بين الأساتذة والطلبة إلى التغيير الإجتماعى و الإتصال الفكري والتقافي، تنمية قيم التعاون

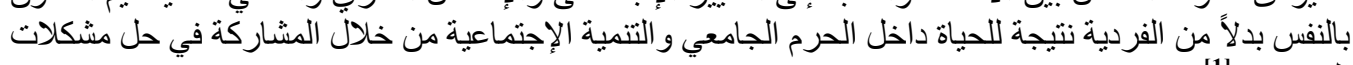
[1] المجنمع

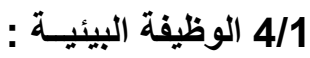

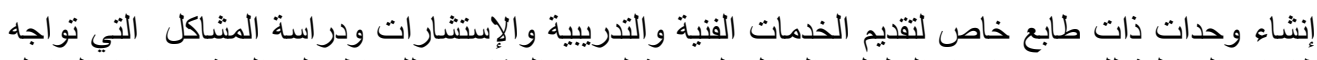

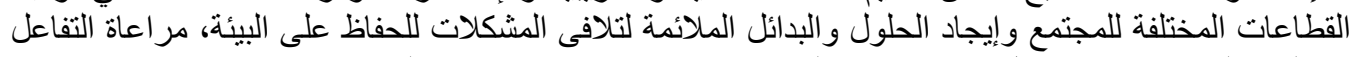

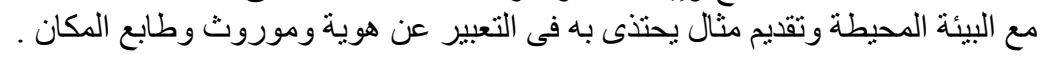

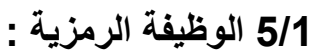

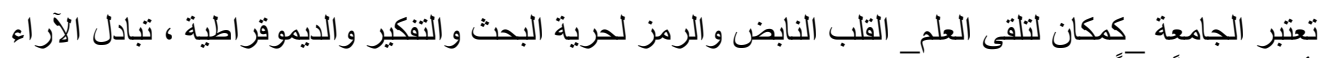

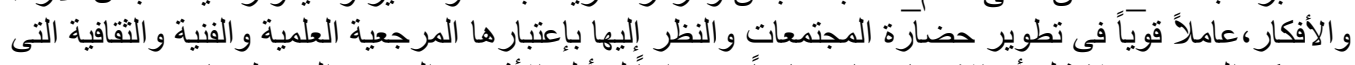

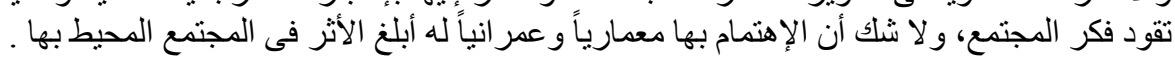

2- جلالية العلاقة بين الهوية المعمارية والعمرانية للمبانى الجامعية والمكان :

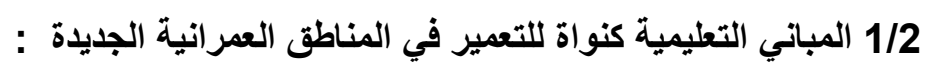

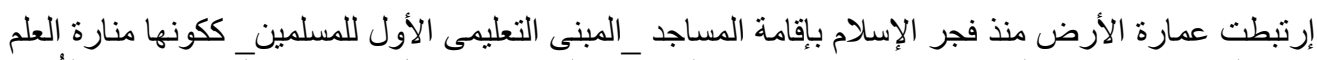

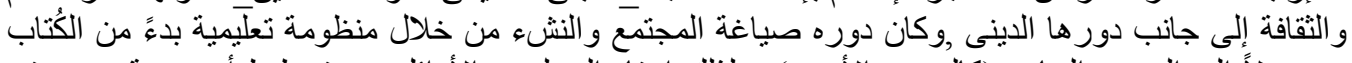

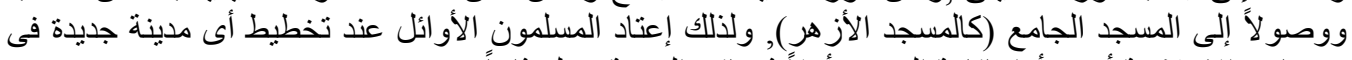
فتوحاتهم الإسلامية أن يبدأوا بإقامة المسجد أو لاً ثم باقى الدئل الدينة حوله ثانياً. 
أما فى العصور الحديثة وفى ضوء تزايد الإهتمام بالعلوم المختلفة والفنون فقد أستوجب ذلك إستقلال المبانى

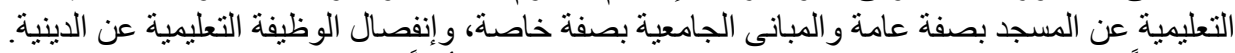

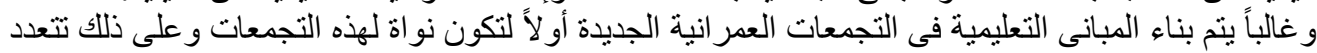

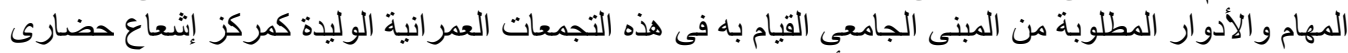

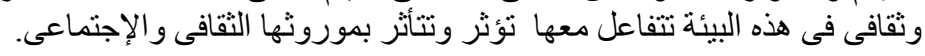

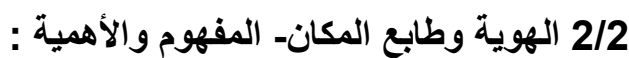

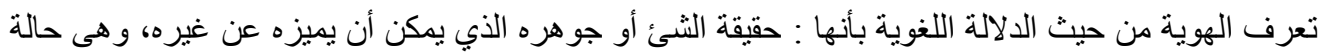

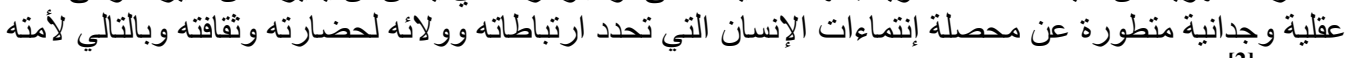

وشعبه. [2]

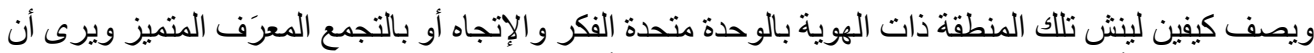

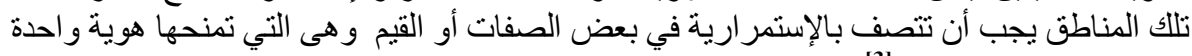

[3].(single Identity)

و الهوية والثخصية إنهما يثيران إلى تلك العناصر المتميزة وغير المتكررة في طوابع الأماكن، وهنا يكون

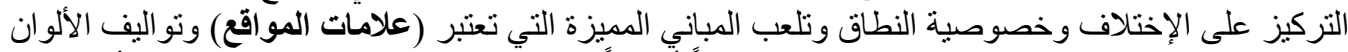

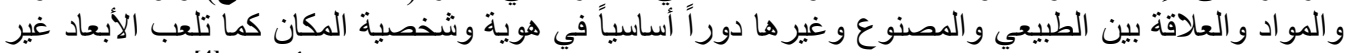

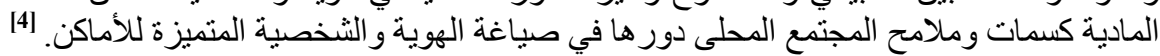

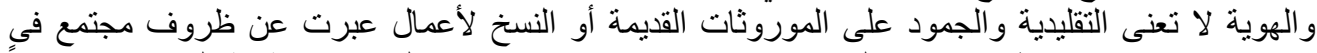

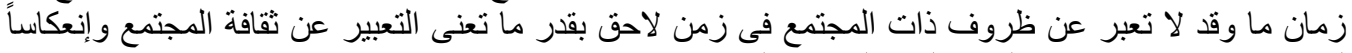

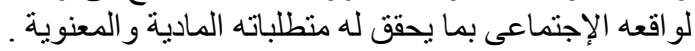

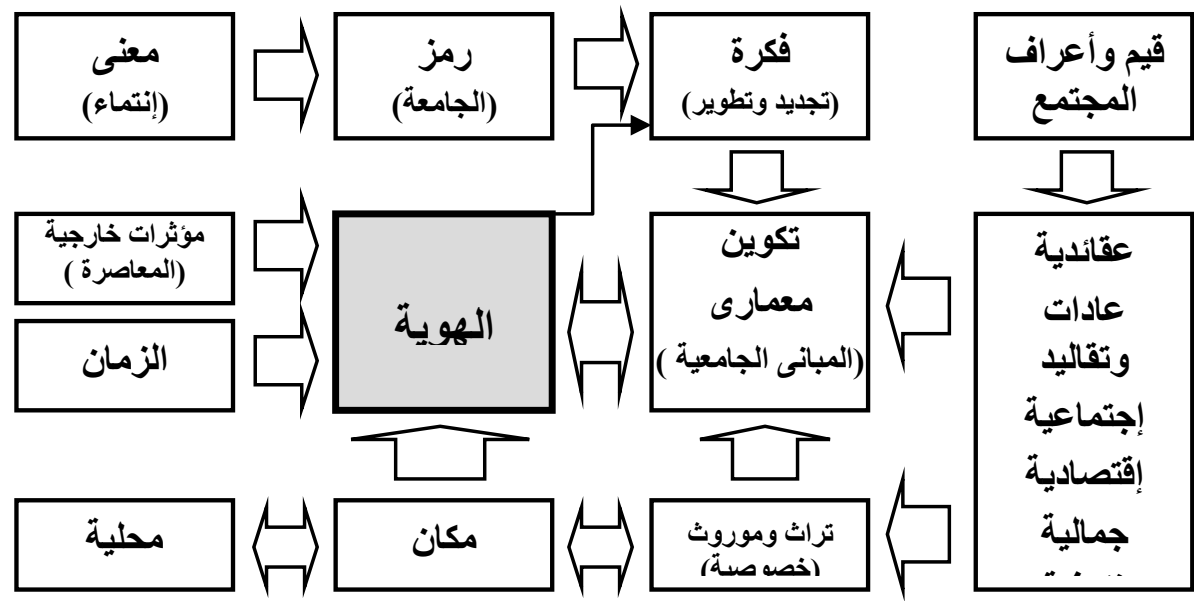

شكل رقم : (1) عناصر و أدوات دعم الهوية المعمارية (الباحث)

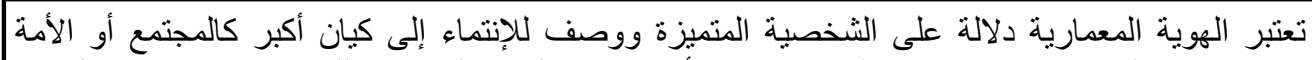

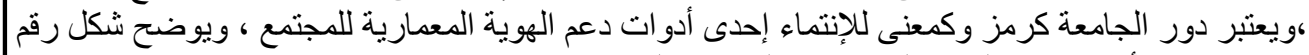

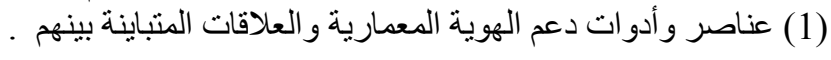

ويعتبر التراث المعمارى_ المعبر عن الهوية وطابع المناطق_بمثابة السجل الحسى والمرجع البصرى المركب

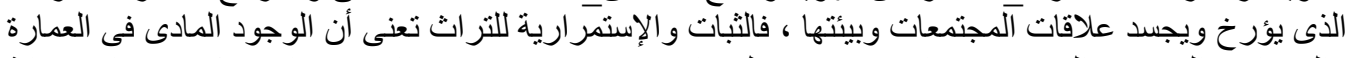

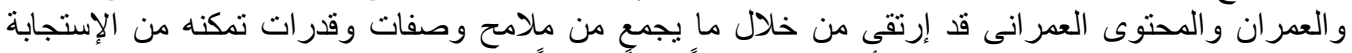

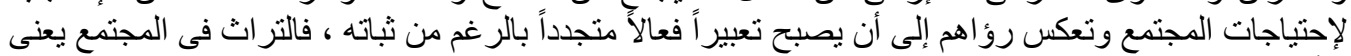

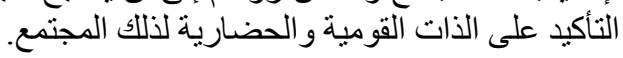


و الهوية من خلال هذا الفهم تعبير عن هوية الإنسان وما يحمله من ثقافة و إنفعالات و أحاسيس إرتبطت بها و عبر الربر

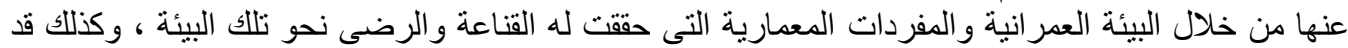

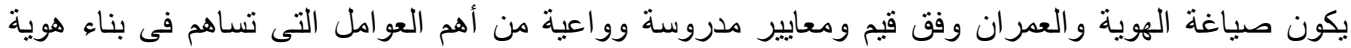

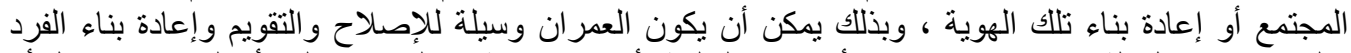

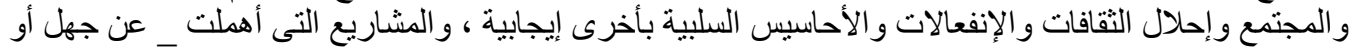

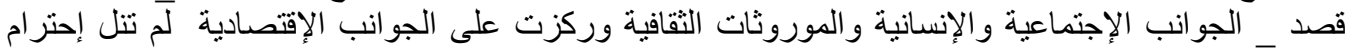

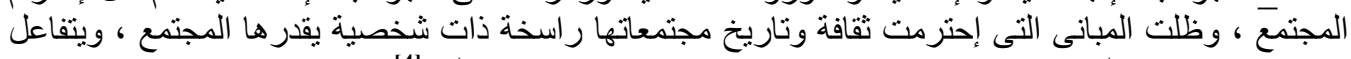

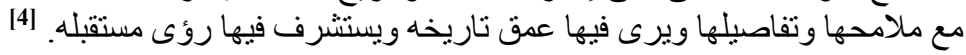

\section{2/2 العلاقة التبادلية بين هوية المكان والمجتمع والهوية المعمارية والعمرانية للمبانى الجامعية :}

\section{1/2/2 الهوية المعمارية والمكان :}

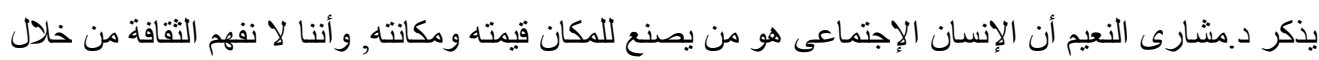

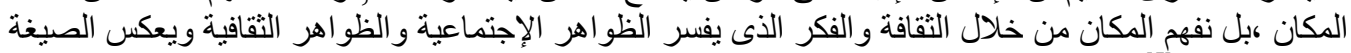
النهائية للتقافة.

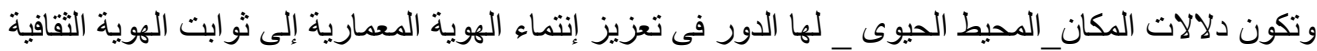

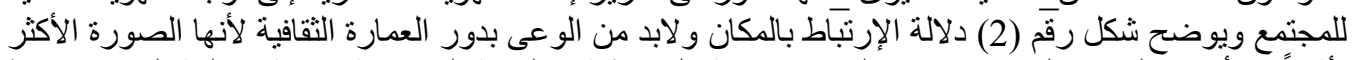

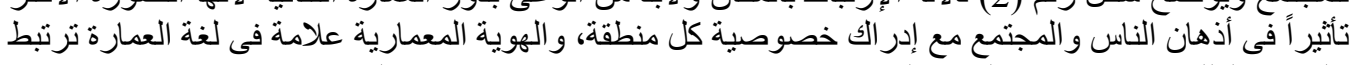

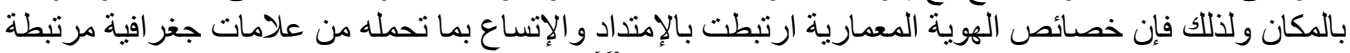

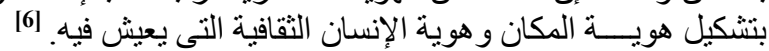

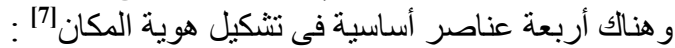

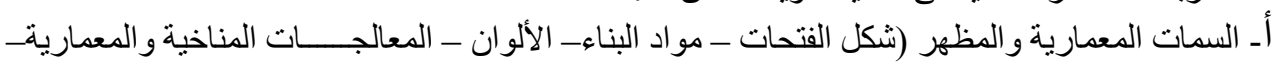

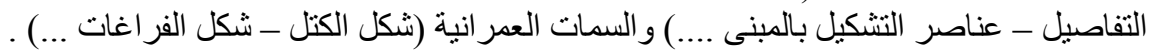
بـ المعانى و الرموز المدركة. ج- التوجهات المختلفة للتعامل مع الهوية المدئ ومدى التأثر بالطابع المحلى.

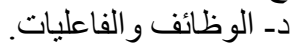

\section{2/2/2 الهوية المعمارية ودلالة الإنتماء للمكان والهوية الثقافية :}

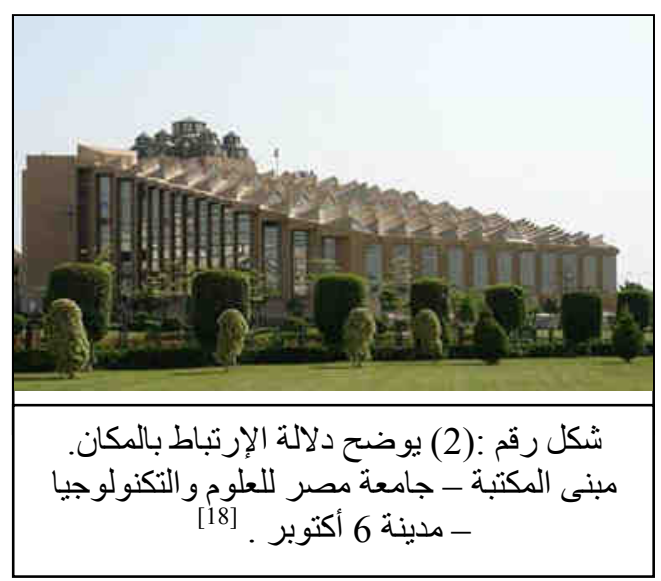

يمثل المكان للإنسان فى البيئة المنزل والمعن والمدرسة

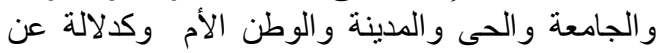

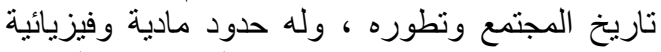

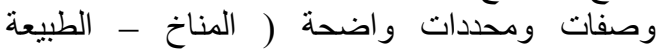

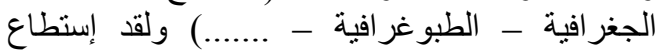

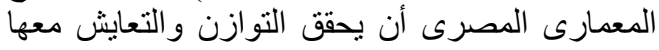

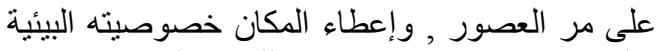

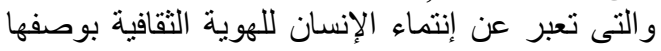

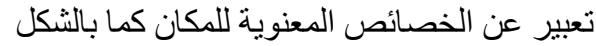

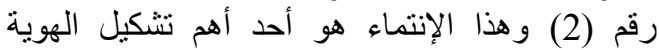

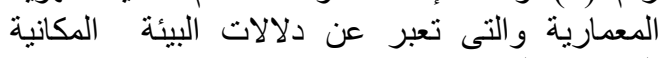
المعمارية المرتبطة بالإنسان . تعبرن

وتعتبر الهوية المعمارية هي دلالة معمارية للمكان ودلالة رؤية ثقافية معمارية قومية ،وملامح التميز التقافى وكي

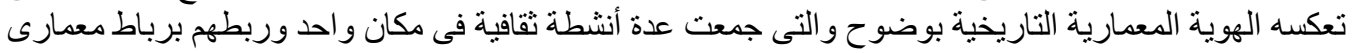




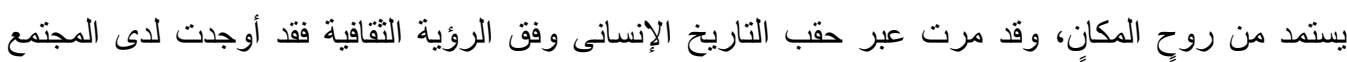

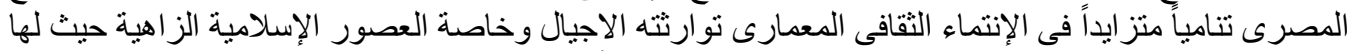

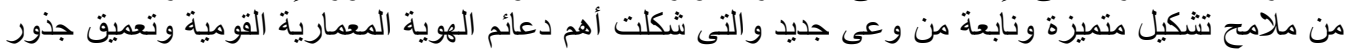

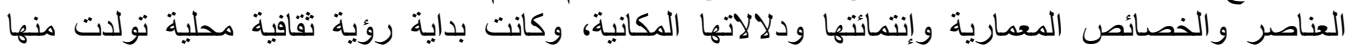

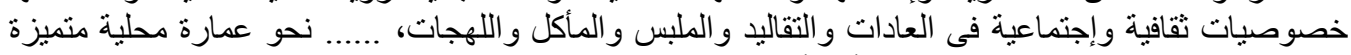

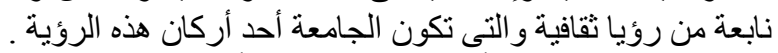

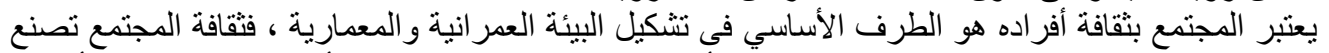

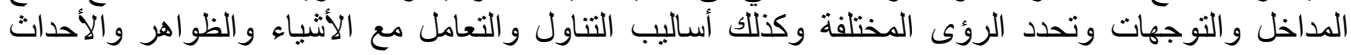

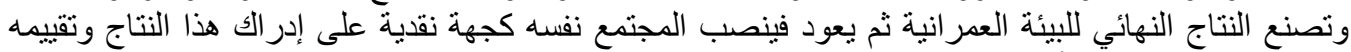

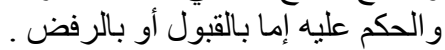

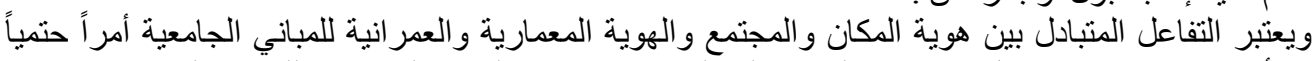

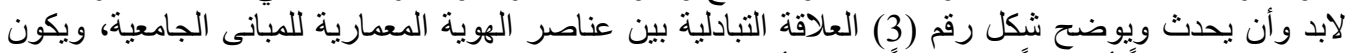

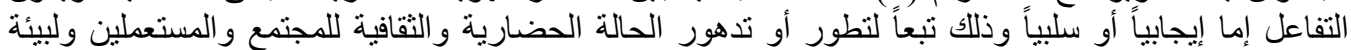
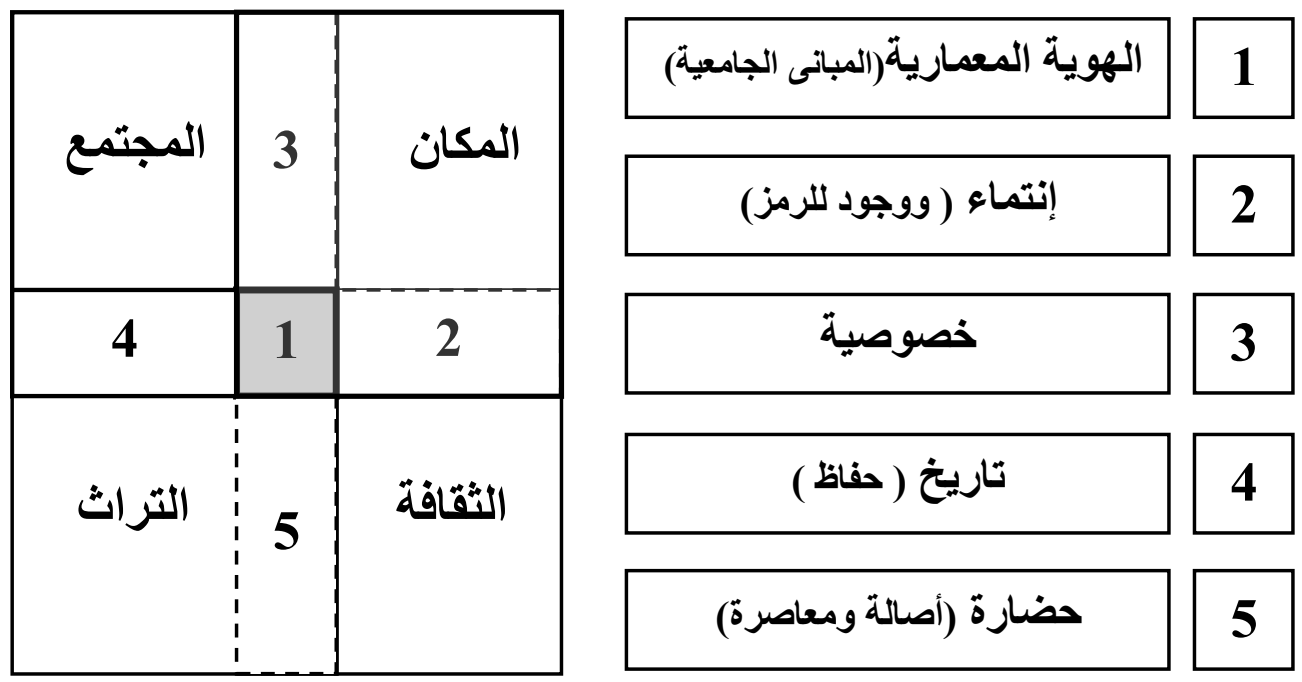

شكل رقم : (3) العلاقة التبادلية بين عناصر الهوية المعمارية للمباني الجامعية (الباحث)

و لابد هنا من التنبه إلى إن سلوكيات المجتمع وثقافته يمكن أن تدفع إلى توجهات فكرية تتناقض مع طابع المكان

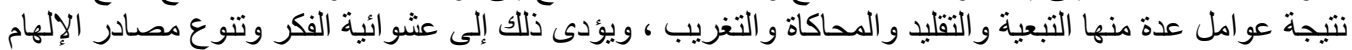

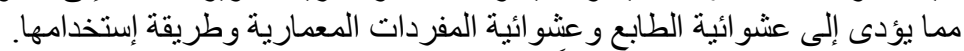

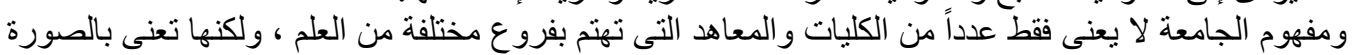

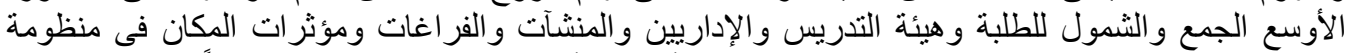

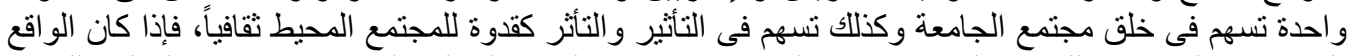

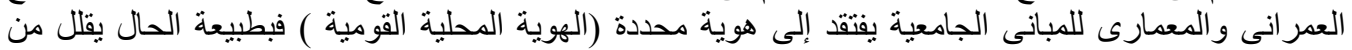

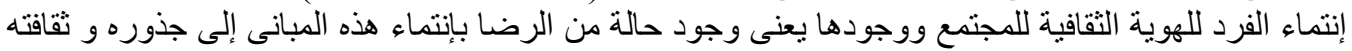

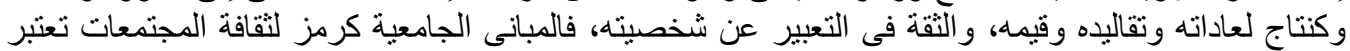

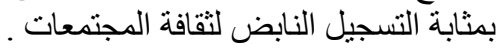




\section{3/2 التوجهات المختلفة فى التعامل مع هوية المبانى الجامعية وأهمية الوعى بطابع المكان:}

و عند التعامل مع قضية هوية وطابع المباني الجامعية تبرز مهمة المعمارى كمهمة ثقافية وفكرية بإعتباره القائم

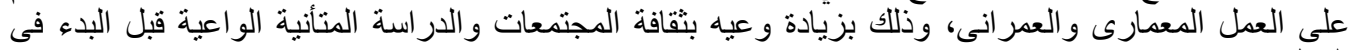

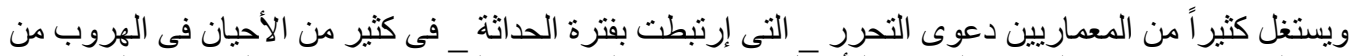

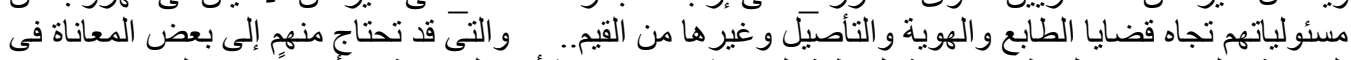

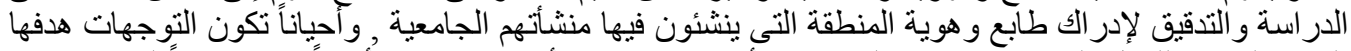

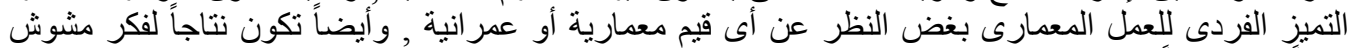

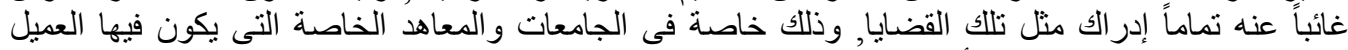

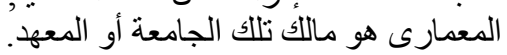

و هنا يمكن القول بأنه لابد وأن تكون " الحرية فى إطار الضوابط " وذلك عن طريق الوعى "بالثوابت والمتغير ات " : المنات

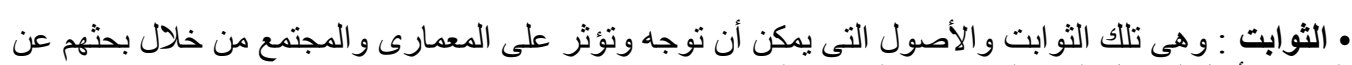

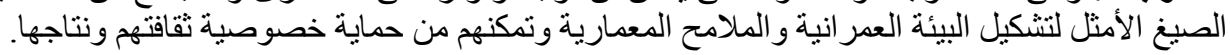

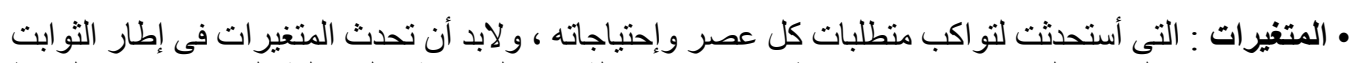

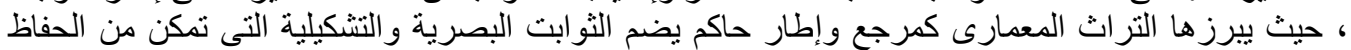
على طابع المناطق.

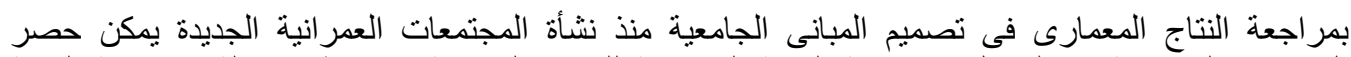

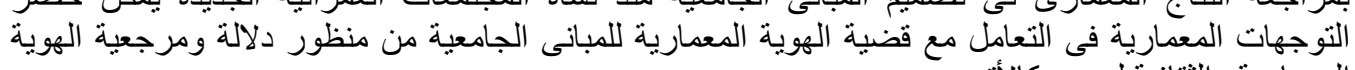

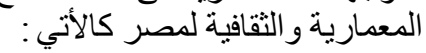
1/3/2 إحترام طابع وهوية المكان :

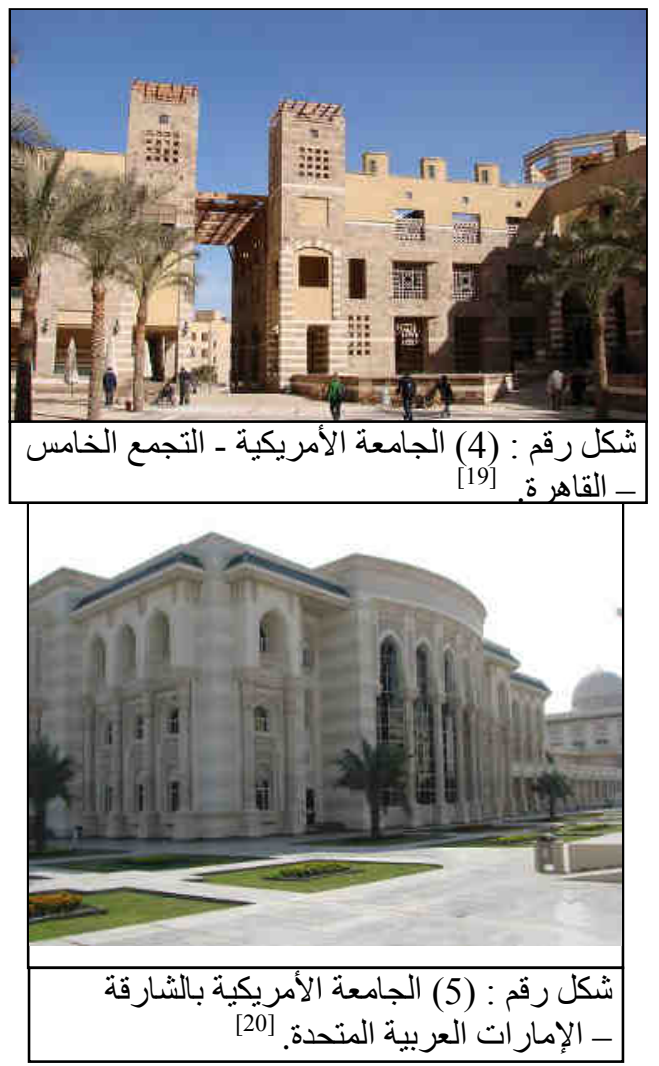

ويعتمد هذا التوجه على البحث عن مفردات العمارة

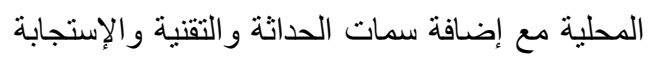

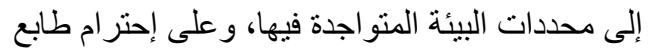

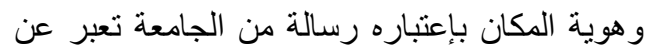

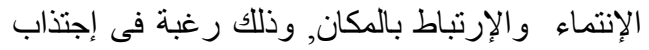

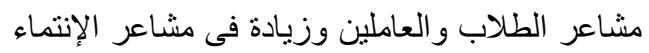

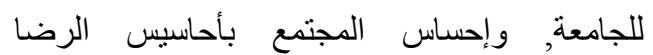
والألفة,.. ومثال ذللك: الجامعة الأمريكية بالقاهرة

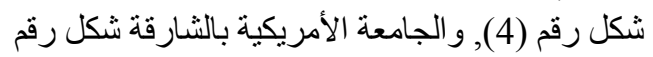

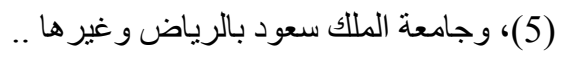
إن التأكيد على هوية المكان يؤكد على النمو الفكرى

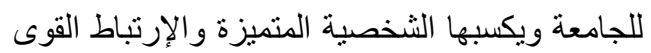
بالمجتمع. 
2/3/2 الإحترام الجزئى لهوية المكان :

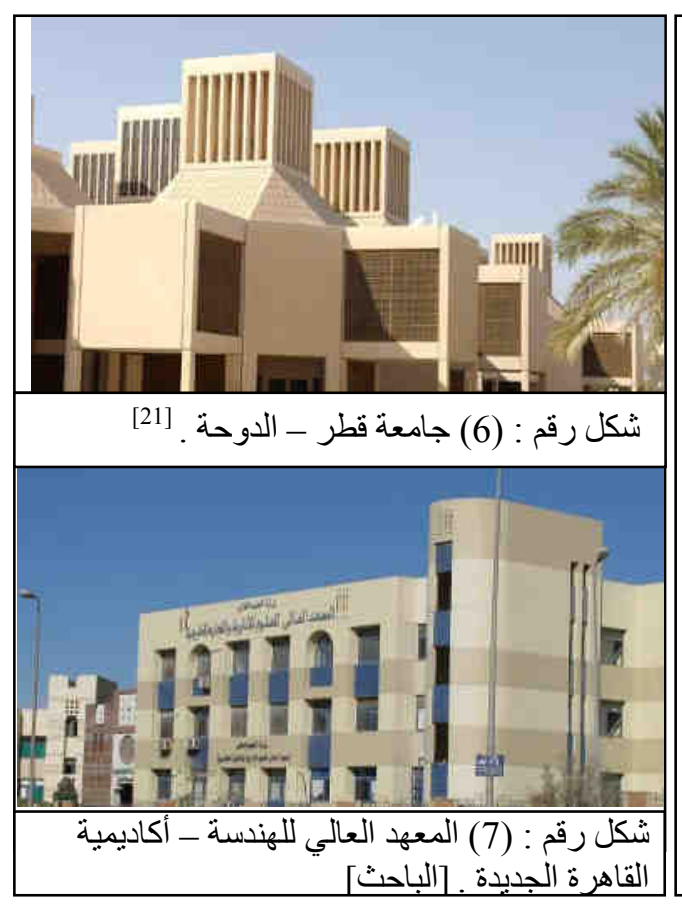

ويعتبر البعض هذا الإتجاه بمثابة إستمرارية لبعض إلبات

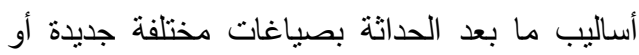
تقليدية , وذللك عن طريق إعادة تعريف الهوية

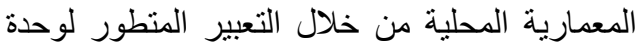

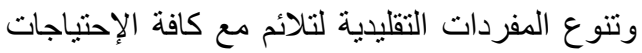
الوظيفية وذلك مثل جامعة قطر بالدوحة شكل رقم (6)، أكاديمية القاهرة بالتجمع الخامس- القاهرة الجديدة شكل رقم (7) ، أكاديمية الثروق بمدية الفينة

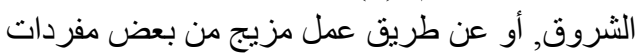
العمارة المحلية مع التكنولوجيا و التبسيط لإضفاء لونياء تأثثيرات بصرية ونفسية تذكر بطابع وهوية المكان الأنية دون الدخول فى حالة التشبع بطابع المكان و الإندماج معه إندماجاً كاملاً.

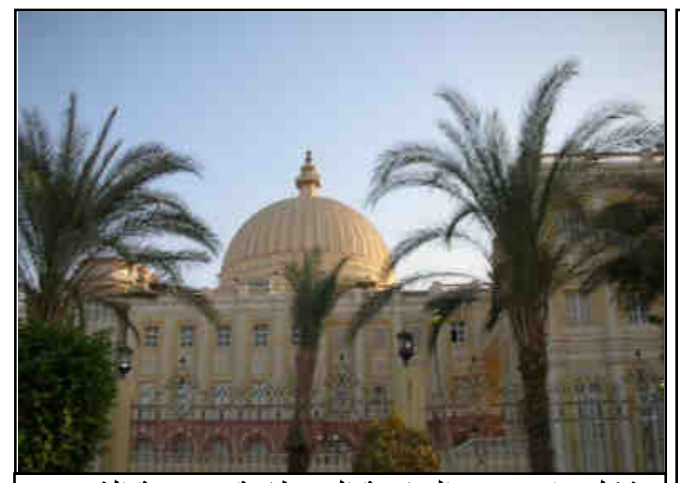

3/3/2 إحترام طابع الجهة المالكة للجامعة :

حيث تسعى الجهة المالكة للجامعة للتأكيد على ثقافتها ونشرها بشتى الوسائل منعكساً ذلك في المى عمارتها,

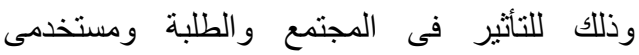
الجامعة, ويحدث ذللك عن طريق إستير اد مفردات

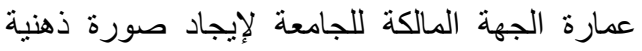
تشبه الإنطباعات الذهنية لمبانى الجامعات العريقة لجاتهات

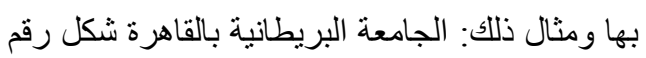

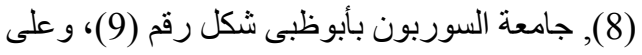
الرغم من وضوح وصر احة التعبير وطبيعة التوجه

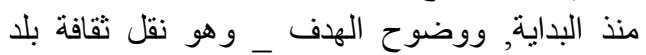
أخرى _ الإ أنه يوحى على الوجه الأخر الأخر بالانفصال

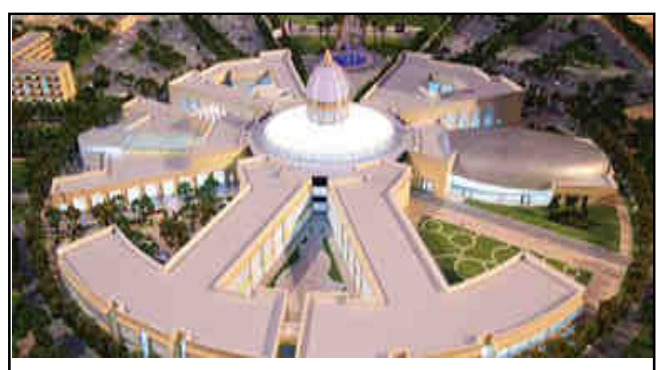

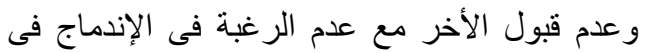
المجتمع المحيط.

شكل رقم : (9) جامعة السوربون (باريسفرنسا)- بأبو ظبى (الامارات العربية المتحدة ) 


\section{4/3/2 إتجاه الحداثة (العمارة الدولية) :}
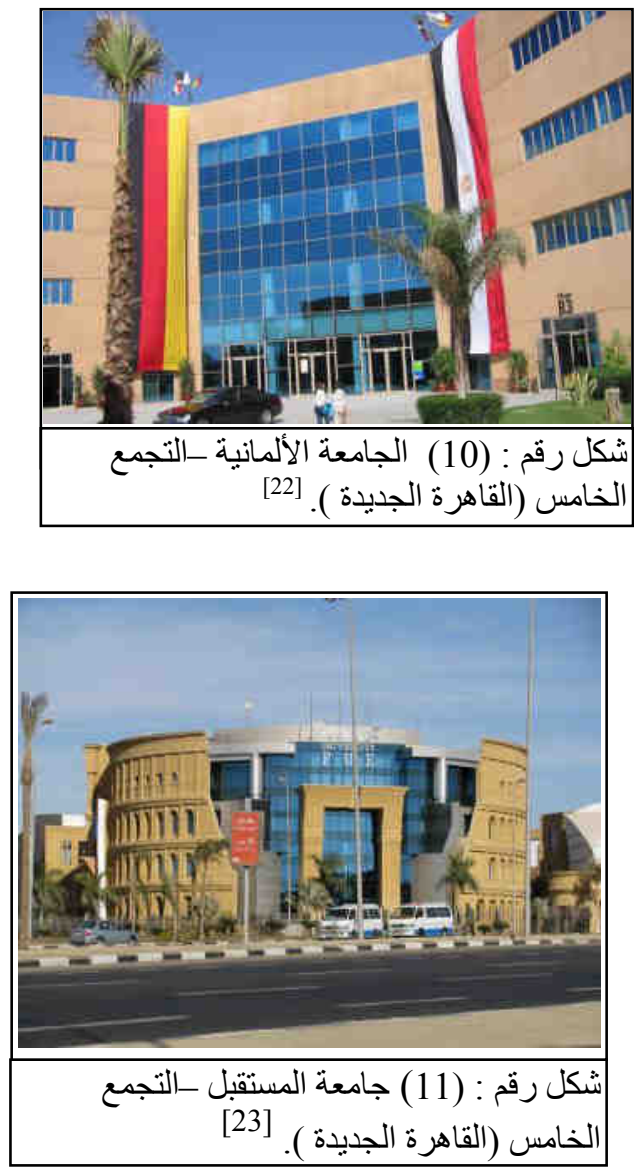

وفى هذا التوجه يتم إستخدام التوجهات التى تعبر عن التطور التكنولوجى ليعطى الجامعة التأثنير إنها حديثة,

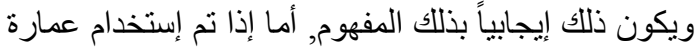

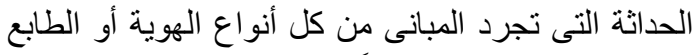

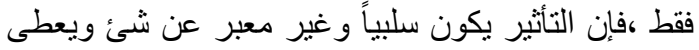

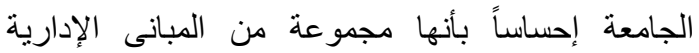
المتجاورة وتكون بلا معنى لدى الطلاب و المجتمع, ومثال الجيال ذلك: الجامعة الألمانية بالتجمع الخامس - القاهرة الجديدة

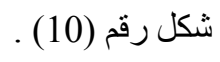

: 5/3/2 خليط بين عدة إتجاهات

يفقد هذا التوجه الروح الثقافية والهوية المحددة للجامعة

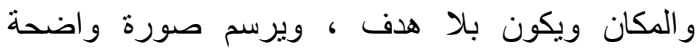

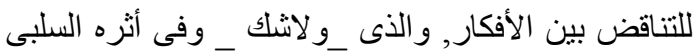

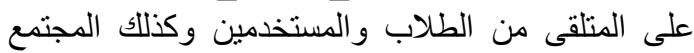

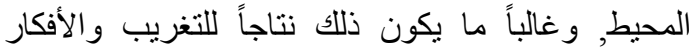

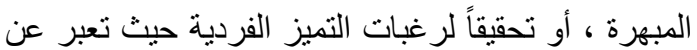

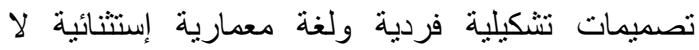
تربطها علاقة بالسياق المحيط بها على الإطلاق ومثال

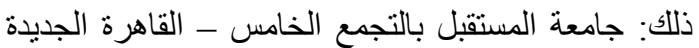
شكل رقم (11).

\section{3- الدراسة التحليلية للأمثئة المختارة :}

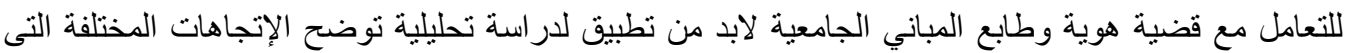

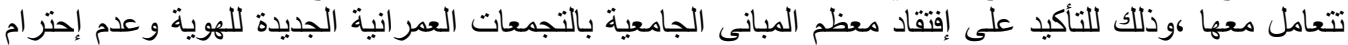
البيئة العمر انية المحلية والموروث الثقافي مع وجود تباين في التوجهات التي تحدد الهوية المعمارية والعمر انية التهاتية

\section{1/3 منهجية الاراسة التحليلية وإختيار الأمثلة:}

سوف تتعرض ورقة البحث الى تحليل نماذج تمثل التوجهات المختلفة للتعامل تجاه هوية المبانى الجامعية يليه

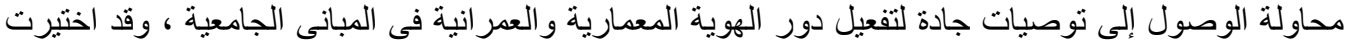

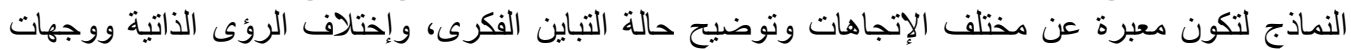

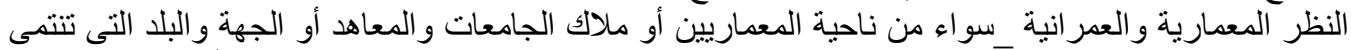

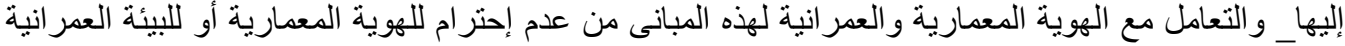


المحلية والموروث الثقافى للمكان المتواجدة فيه ويوضح جدول رقم (1)، (2)، (3)، (4)، (5) (5) تحليل لنماذج

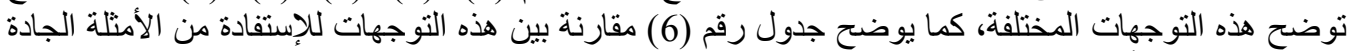

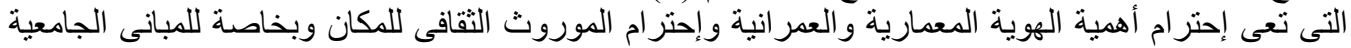

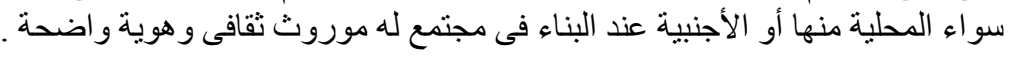

1/1/3 جدول رقم : ( 1 ) الجامعة الأمريكية (نموذج توجه إحترام طابع وهوية المكان)

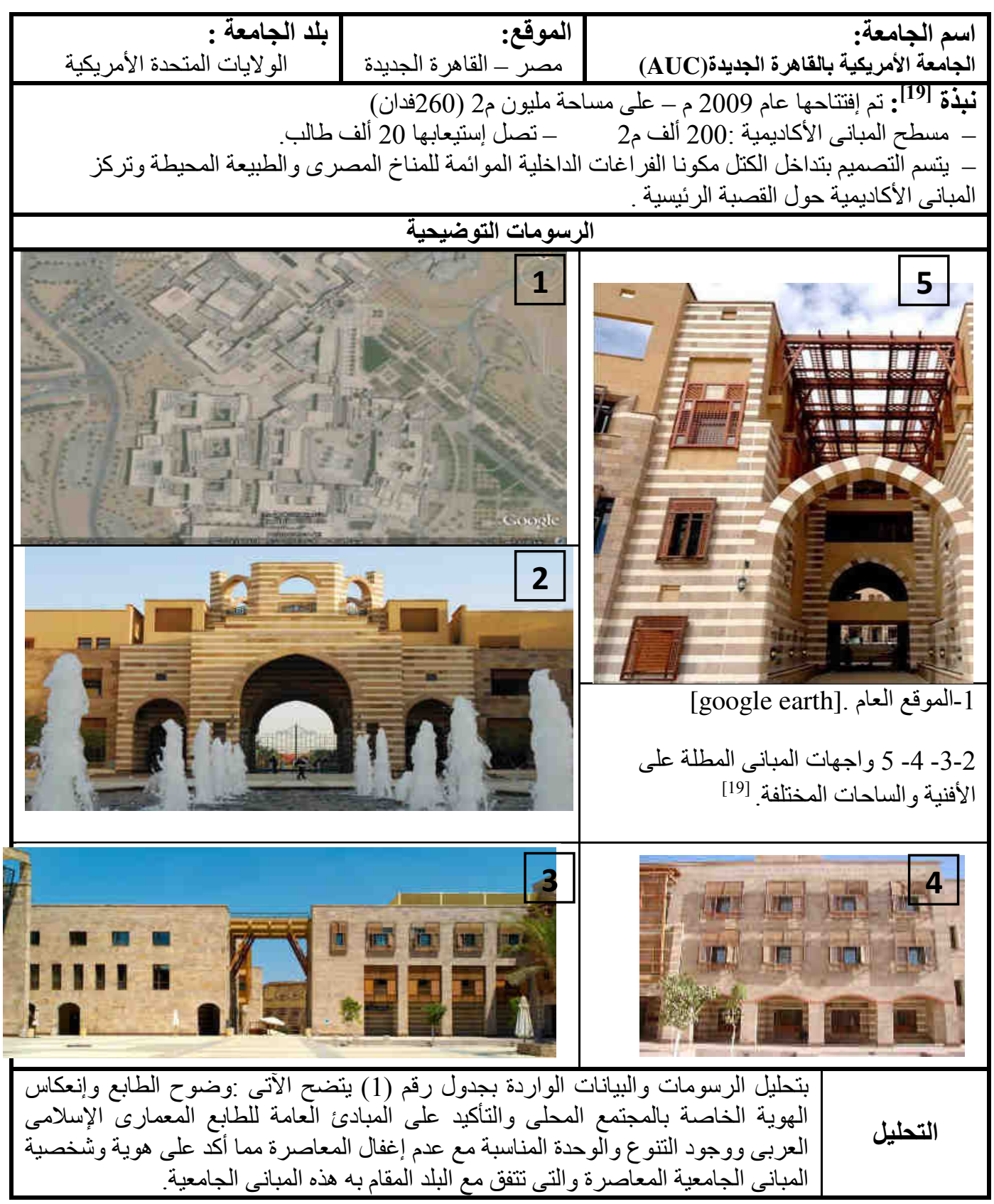


2/1/3 جدول رقم : ( 2 ) أكاديمية القاهرة الجديدة (نموذج توجه الإحترام الجزئى لهوية المكان)

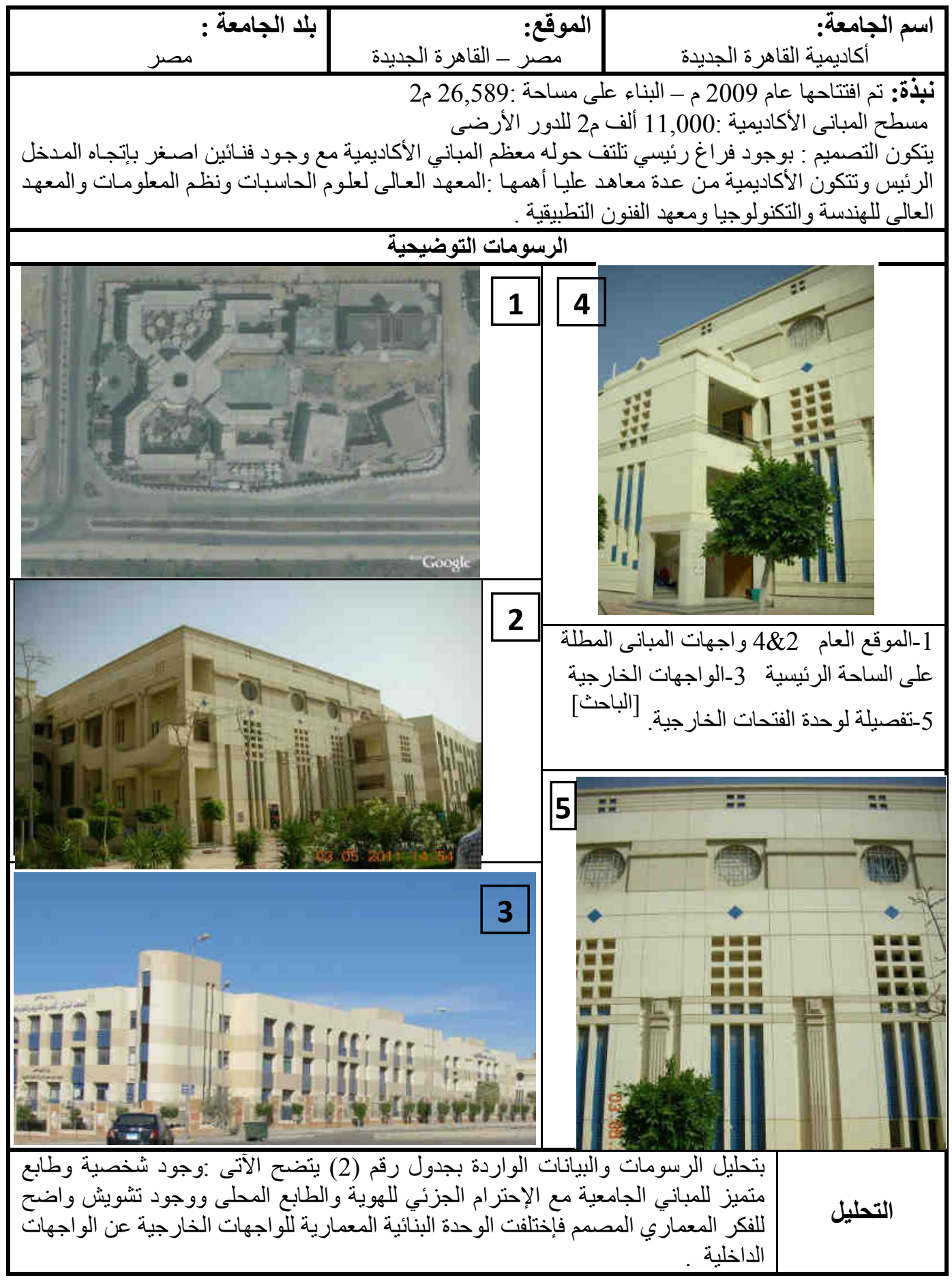


3/1/3 جدول رقم: ( 3 ) الجامعة البريطانية (نموذج توجه إحترام طابع الجهة المالكة للجامعة)

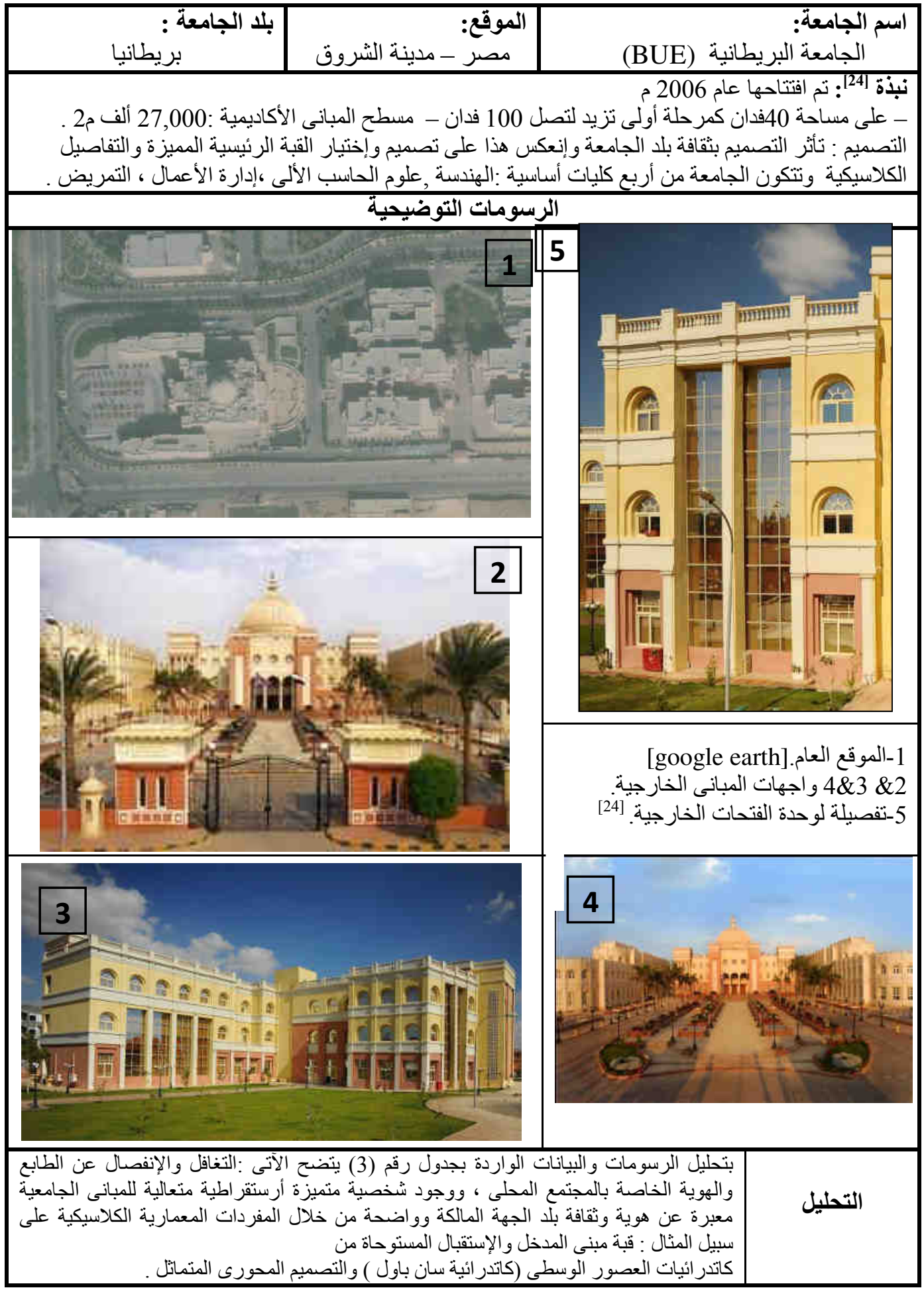


4/1/3 جدول رقة : ( 4 ) الجامعة الألمانية (نموذج توجه عمارة الحداثة (العمارة الدولية )

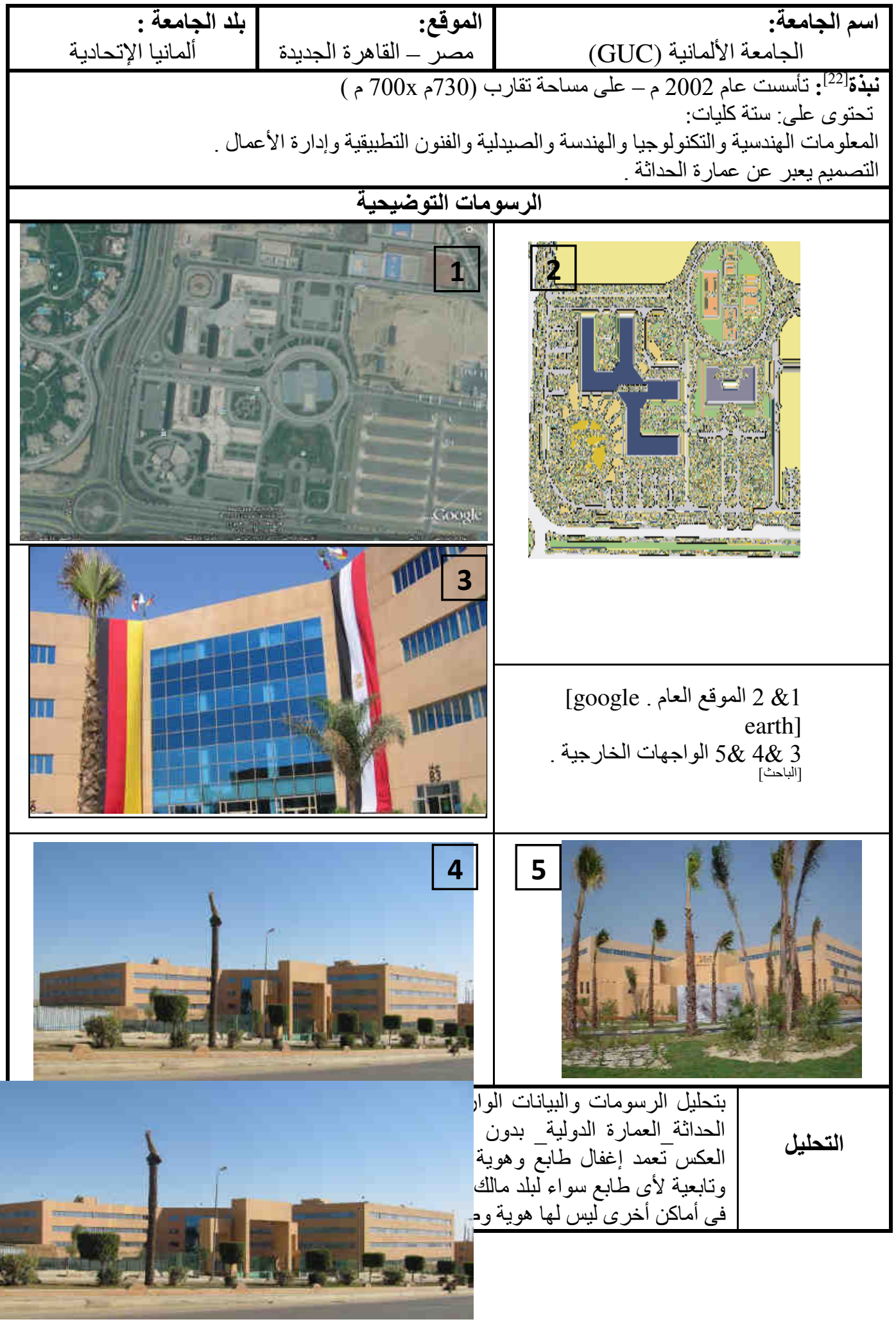


5/1/3 جدول رقم : ( 5 ) جامعة المستقبل (نموذج توجه خليط بين عدة إتجاهات)

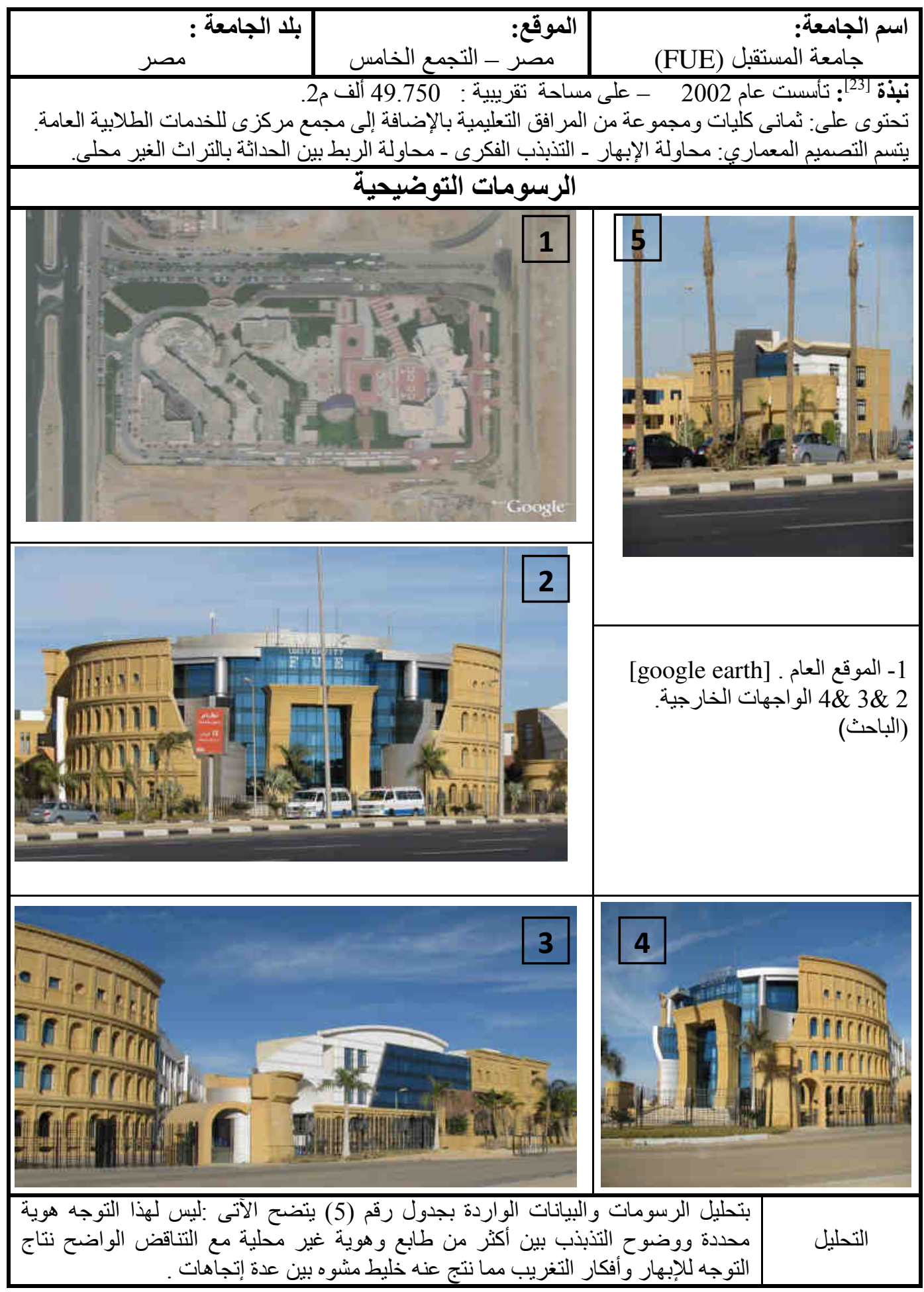


2/3 جدول رقم : (6) مقارنة بين أمثلة التوجهات المختلفة فى التعامل مع هوية المبانى الجامعية

\begin{tabular}{|c|c|c|c|c|c|c|}
\hline المستقبــلـ جامعة & الألماتئلةة & 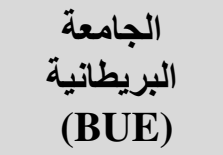 & أكاديمية & $\begin{array}{l}\text { الأمريكيةة } \\
\text { (AUC) }\end{array}$ & \multicolumn{2}{|c|}{ عناصر } \\
\hline 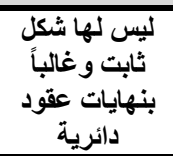 & 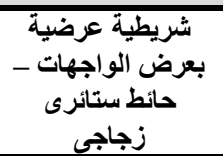 & كلاسيكية غائرة & شريطية طولية & مربعة - غائرة - مشربيات & الفتحات & \\
\hline القالقواد التقليديةلة & خكسية حجر صناعى مونى & 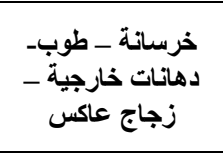 & خالحجر الصناعى ـ تكسية & 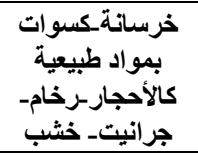 & البناء & \\
\hline المزج بين البيج & (سيجمون غائل للحمرة) & فامث- أبيض- سيمون زجاج & بالأنرق وتبعضي والبنى & 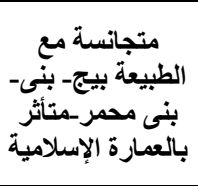 & الألوان & $c^{5}$ \\
\hline 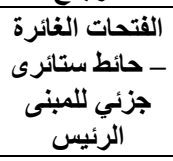 & لا يناخية أى معالجيات & 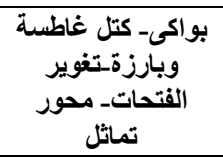 & كتلاصقة ولموعات البود & كتلاصقة لتوفيرت & المعالجات & $\underline{E}$ \\
\hline وقيقة لأكثر من مناصيل & لا يوجد تفاصيل & ( أرستقراطية معمارية إنجلية & 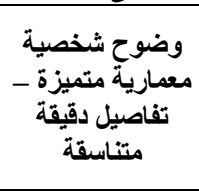 & النابعة من هوية التفاصيل & التفاصيل & \\
\hline تثكيلى من نمتلف بين & للا للتشكيل سلامى الفتحات العرضية & 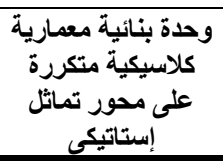 & متكررة وحلة سمة بنائة & و والتفاعل بين الظة والظة & عنتكيل & \\
\hline كتلى كلاسيكى -تلاخلى & 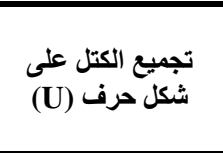 & راسخة على متلى محور & تجميع الكتل حول كبيسة & 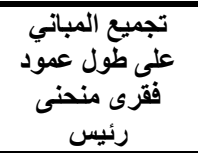 & الكتل & $\varepsilon$ \\
\hline شكل الفراغوح & مفتوحة من جدة أفنية & وأفنية داخل رائيسية أمام ضيقة & الملاعب وسيسية بهاحتان & متنوعة المسطح وأفنية & الفراغات & E \\
\hline & & & & - & إحترام هوية & $E^{2}$ \\
\hline & & & - & & لهوية المكاني & $\underline{E}$ \\
\hline & & - & & & الجترة المالكة هوية & 它 \\
\hline & - & & & & إتجاه الحداثة & t5 \\
\hline - & & & & & عدة اتجاهينات & \\
\hline & & & & - & متأثر & $9 ?$ \\
\hline - & - & - & - & & غير متأثر & \\
\hline
\end{tabular}




\section{4- الإستفادة من دور الهوية الإيجابى وخاصة بمجتمع له موروث ثقافي وهوية واضحة:}
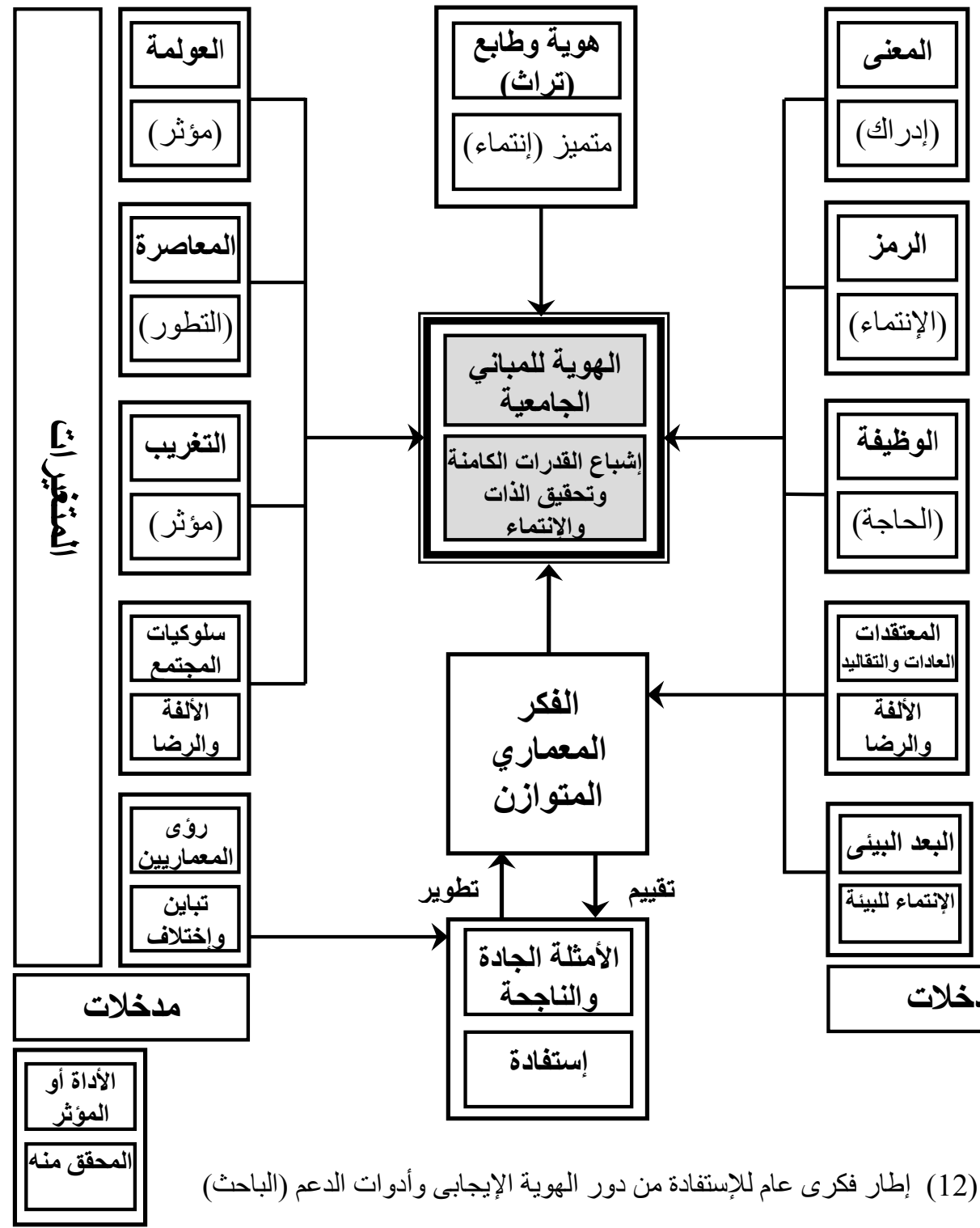

وتحقيق الذات

و الإنتماء الأب

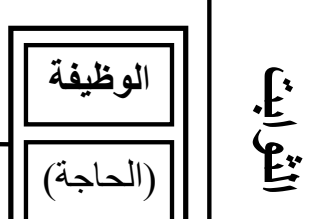

في ضوء ما تقدم من التحليل يقترح الباحث إطار فكرى عام نحو تفعيل الإستفادة من دور الهوية الإيجابي

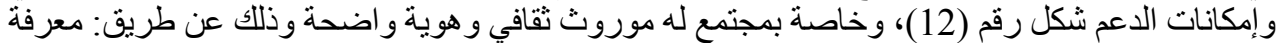

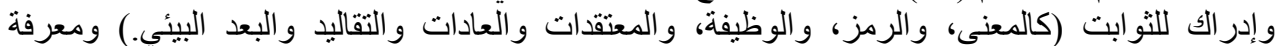

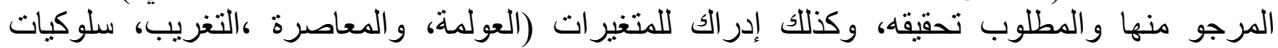

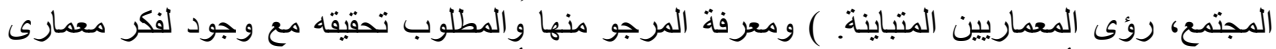

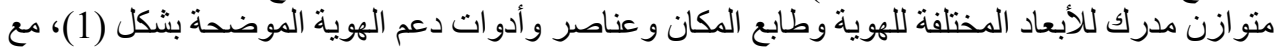

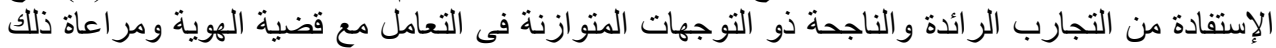


: 1/5

أـ إثتنمال مفهوم الجامعة على الجمع والثمول للطلبة وهيئة التدريس والإداريين و المنشآت و الفراغات

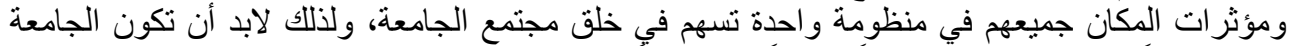

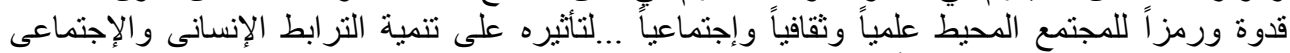

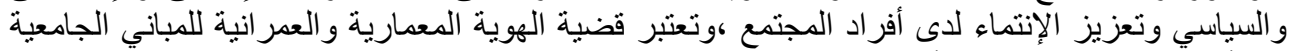

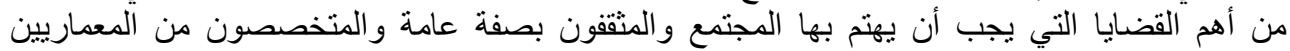

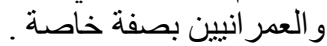
بـ إختلفت التوجهات فى التعامل مع هوية المباني الجامعية وقد ظهر ذللك من خلال الدراسة التحليلية فى عدة توجهات هي : بلت التوجن

$$
\text { - }
$$

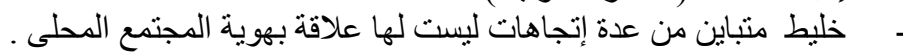

\section{وقد أظهر ذلك الأتي :}

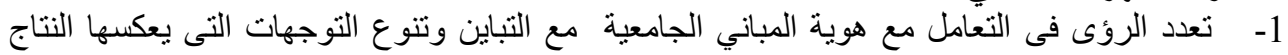

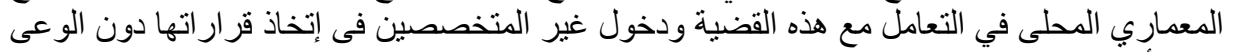

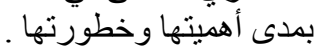

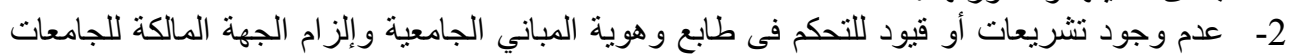

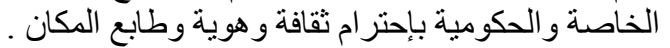

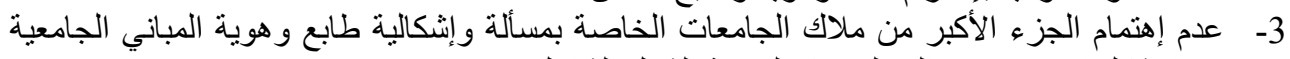

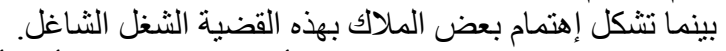

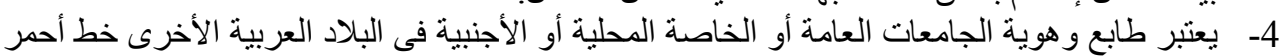

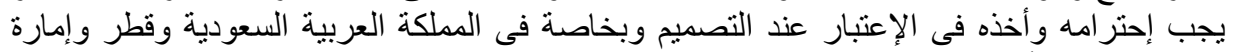

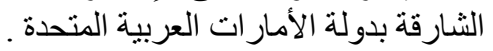

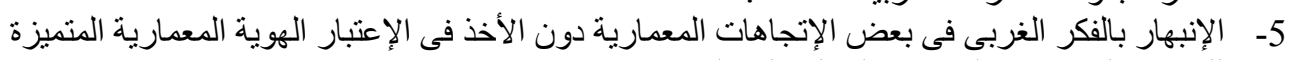

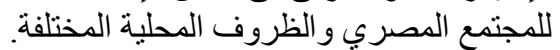

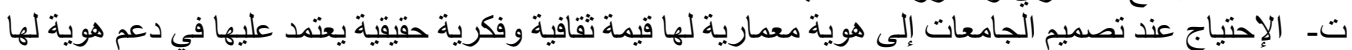

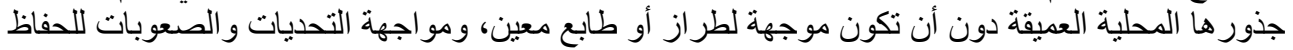

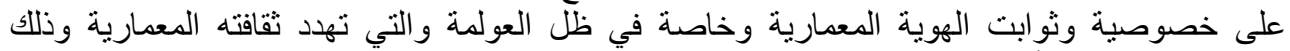

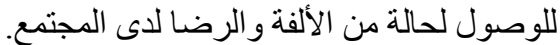

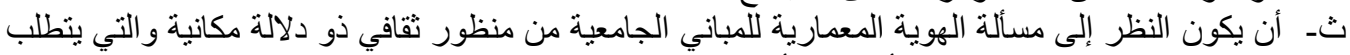

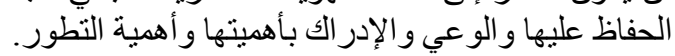

\section{2/5 التوصيات : 2/5}

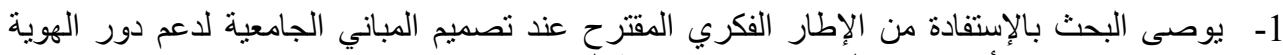

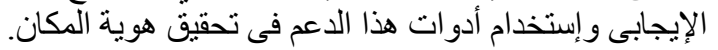

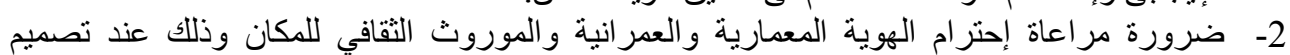

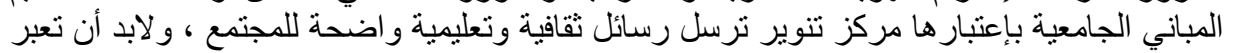

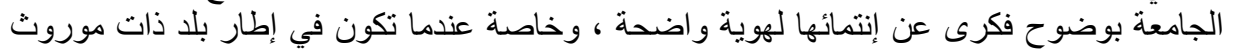

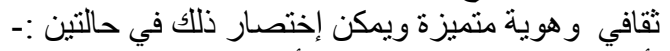

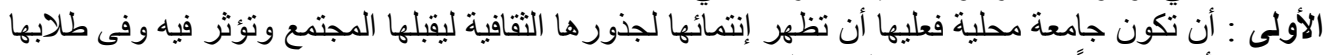
تأثير إيجابياً وتعزز الإنتماء الثقافى لديهم . 
الثانية : أن تكون جامعة أجنبية ، وفى هذه الحالة يكون التعبير المعماري والعمر اني تبعاً لتوجهها ورسالتها و أهدافها كالأتي : أنكون :

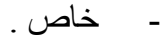

- - أن يكون هدف الجامعة هو الإندماج في المجتمع و التفاعل مع مقوماته الثقافية، فيكون من الأفضل

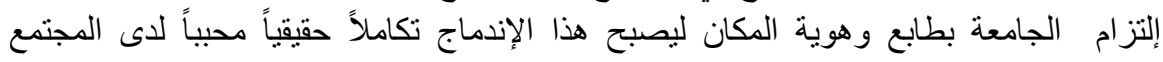
المضبف التز

3- تفعيل دور الهوية المعمارية والعمر انية للمنشآت الجامعية سواء المحلية أو الأجنبية عند البناء فيى

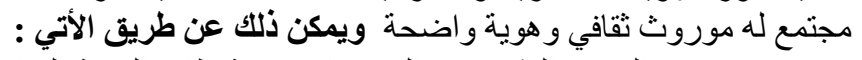

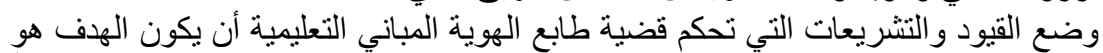

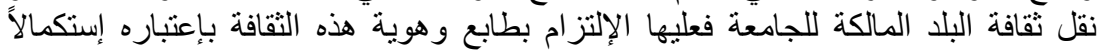

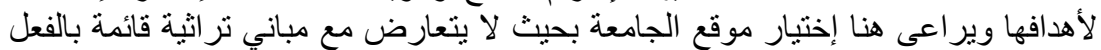

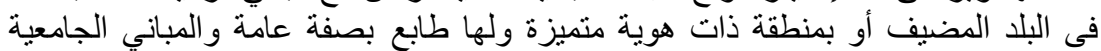

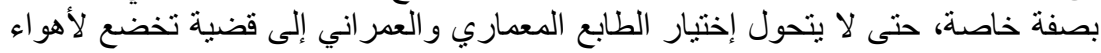
المستثمرين. إيجاد حافز معنوي لأصحاب وملاك الجامعات الخاصة لتشجيعهم لتفعيل دور و أهمية الهوية

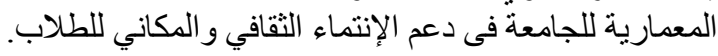

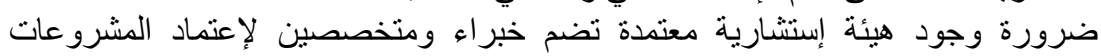

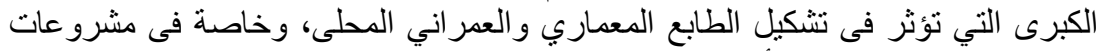

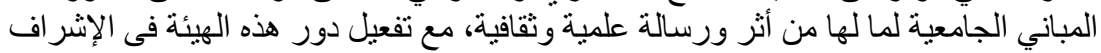
و المتابعة عند التنفيذ.

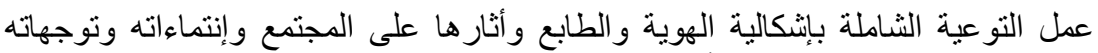

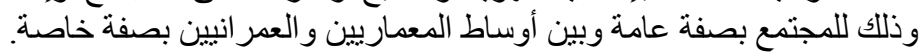

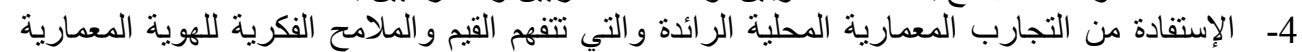

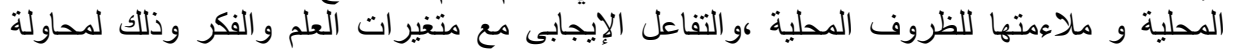
التطبيق و إعادة التقييم لتحقيق عملية التطوير و الإستمر ار. لإني

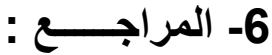

ـ أولا : الكتب والدوريات:

[1] محمود طه محمود سليم، الفر اغات المفتوحة في الجامعــات ( در اســـــــة تحليلية ) ، رسالة ماجستير، جامعة حلوان، 1995 م. 199

[2] د.يحيى الوزيرى، الهوية والطابع المعماري بين الثكل و المضمون، مقالة الكترونية، سبتمبر 2010 م.

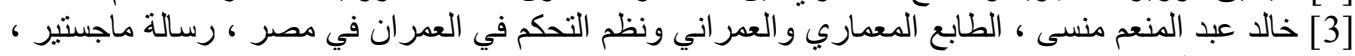

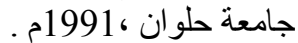

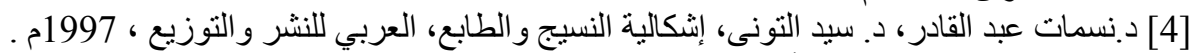

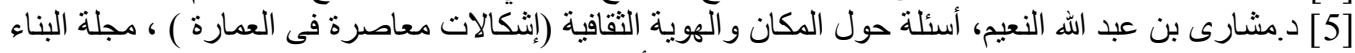

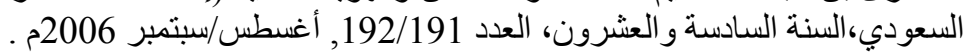

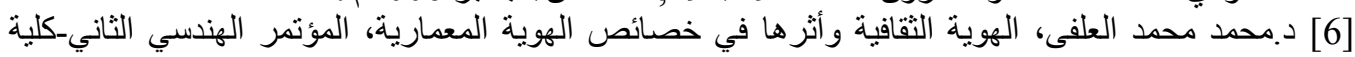

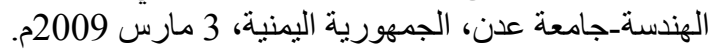

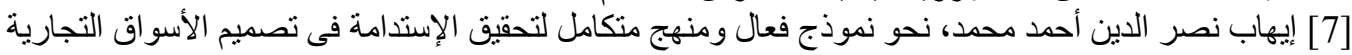

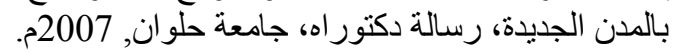

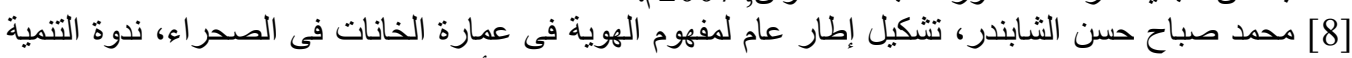

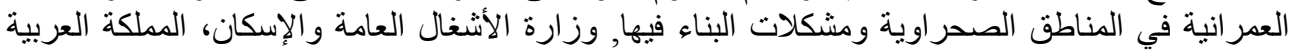

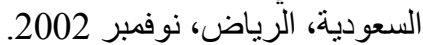


[9] د.مشارى بن عبد الله النعيم، الحديث فى الهوية المجتمعية للمعماري العربي، مجلة البناء السعودى، السنة

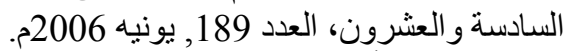

[10] د. هشام جلال أبو سعدة، نسق القيم الإنسانية في الفر اغات العمر انية للعدينة العيدة العربية الإسلامية ،بحث منشور،

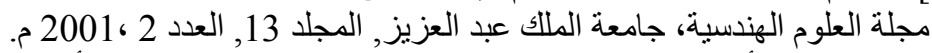

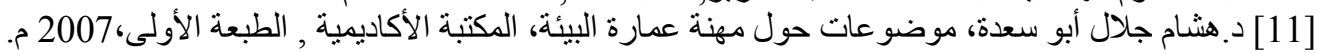

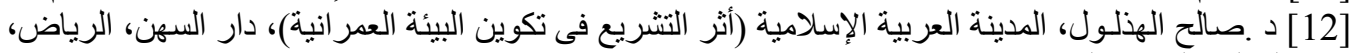

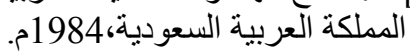

[13] على حمدان، إثنكالية الهوية والإنتماء، المركز الأستر الي العربي للار اسات السياسية, الطبعة الأولى، 2005 [14]" عفيف بهنسى، ما بعد الحداثة والتراث فى العمارة العربية الإسلامية، عالم الفكر، المجلد 27،العدد الثاني، 1981م.

[15] Identity By Design, Georgia Butina and Ian Bentely, Elsavier Ltd, First Edition, 2007.

[16] Identity Community, Culture, Difference, jonathan Rutherford lawrence \& Wishart London, 1990.

[17] University Builders, Martin Pearce, Wiley academy, First Edition, 2001.

\section{ـ مثانياً: المواقع الإكترونية}

[18] http://www.must.edu/library.php

[19] http://www.aucegypt.edu/

[20] http://www.aus.edu/

[21] http://www.qu.edu.qa/theuniversity

[22] http://www.guc.edu.eg/

[23] http://www.futureuniversity.edu.eg/

[24] http://www.bue.edu.eg/
(Last Access 10/01/2012) .

(Last Access 12/09/2011).

(Last Access 15/08/2011).

(Last Access 12/10/2011).

(Last Access 11/09/2011).

(Last Access 13/09/2011).

(Last Access 11/09/2011). 